\title{
The Benefits of Integrated Eye Tracking with Airborne Image Recorders in the Flight Deck: A Rejected Landing Case Study
}

\author{
Wen-Chin $\mathrm{Li}^{1}$, Graham Braithwaite ${ }^{1}$, Thomas Wang ${ }^{2}$, Morris Yung ${ }^{2}$ and Peter Kearney ${ }^{3}$ \\ ${ }^{1}$ Safety and Accident Investigation Centre, Cranfield University, Bedfordshire, U.K. \\ ${ }^{2}$ Aviation Safety Council, Republic of China \\ ${ }^{3}$ Irish Aviation Authority, 11-12 D'olier Street, Dublin, Ireland
}

\begin{abstract}
Aircraft accident investigation has played a pivotal role in improving the safety of aviation. Advances in recorder technology, specifically Cockpit Voice Recorders (CVRs) and Flight Data Recorders (FDR) have made a huge contribution to the understanding of occurrences for accident investigators. However, even these recorders have limitations such as the evidence they provide about pilots' situational awareness (SA) or behaviours. Supplementary audio and video recording data in the flight deck have been discussed for many years and whilst there continues to be debate among regulators, operators, manufacturers and pilot unions, the International Civil Aviation Organization (ICAO) has mandated Airborne Image Recorders (AIR) from 2023. The purpose of installing such systems is to provide evidence of crew operational behaviours in terms of both human-human and human-computer interactions (HCI) on the flight deck. Video alone is unlikely to provide sufficient evidence for investigators. This study examines the additional value that eye-tracking technology may provide through the case study of an accident involving an Airbus A330-300 aircraft which experienced a rejected landing. Currently, the investigation of such events, where crew interaction with automation is critical to their SA, relies heavily on interview data. Such data may be unavailable (in the case of serious injury) or unreliable (based on hindsight bias). By integrating eye tracking technology into an AIR, accident investigators will potentially gain a better understanding of pilots' visual scan patterns across flight deck instrumentation. This has implications for flight deck and procedural design as well as training and simulation.
\end{abstract}

Keywords: Accident Investigation; Airborne Image Recorders; Eye Tracking; Human-Computer Interactions; Visual Behaviours

\section{Introduction}

The International Civil Aviation Organization (ICAO) has debated the requirement for flight crew machine interface recordings to be included in its international Standards 
and Recommended Practices for the Operation of Aircraft (known as Annex 6) for many years. The objective of implementing an airborne image recorder (AIR) is to provide supplementary data to an aircraft's conventional flight recorders - the cockpit voice recorder (CVR) and flight data recorder (FDR) (ICAO, 2010). The cockpit image recorder can facilitate accident investigators in examining human performance and human-computer interactions (HCI) in the flight deck (Costa, 2019; ICAO, 2013). The US national accident investigation organisation, the National Transportation Safety Board (NTSB) proposed the idea of cockpit image recordings several times over the last 15 years. However, such proposals have largely been opposed, especially by pilots' unions who typically view such technology as an invasion of privacy. This was despite the fact that the NTSB proposals noted that the recordings would not capture images of actual pilot movements, but rather would focus on capturing critical flight information being displayed to the pilots and system responses to pilots inputs (NTSB, 2015).

The parameters captured by conventional CVRs and FDRs do not provide investigators with accurate information of pilots' attention distribution, SA or HCI issues relating to aeronautical decision-making (ADM) on the flight deck (Wang, Li, \& Lin, 2017). ADM is defined as a systematic approach to the mental process used by aircraft pilots to consistently determine the best course of action in response to a given set of circumstances (FAA, 1991). ADM involves the pilot's visual attention in the flight deck, SA, choice among alternatives and risk management (Orasanu \& Connolly, 1993). Decision errors have been found to contribute to $35 \%$ of all nonfatal and $52 \%$ of all fatal general aviation accidents (Jensen \& Benel, 1977). The techniques for investigating decision-making and human-computer interaction are based on subjective approaches, such as interviews with pilots who survive accidents or assessments based on an investigator's experience if the pilots have died in the accident ( $\mathrm{Li} \&$ Braithwaite, 2019). Research on the topic of "confirmation bias" demonstrates that human operator's tend to collect information related to what they already believe (Hunt, Rutledge, Malalasekera, Kennerley, \& Dolan, 2016). Confirmation bias is as applicable to pilots as it is to accident investigators, especially where evidence is limited.

The CVR does not always provide adequate information to the accident investigation, as it only records audio information. Pilots may not verbalize all their actions, intentions or thoughts as they respond to urgent situations (Elling, Lentz \& de Jong, 2012). The quality of pilot decision-making is a function of the tasks at hand and the dynamic operational environment. The application of eye-tracking technology to the flight deck has proven itself to be a constructive development as it can be used to identify a pilot's attention distribution and SA based on human-computer interactions (Robinski \& Stein, 2013). The concept of investigating visual behaviours related to cognitive processes 
has been validated by many previous researchers including automated flight deck (Sarter, Mumaw \& Wickens, 2007), tracing processes in decision-making (Glaholt \& Reingold, 2011), and alerting design in air traffic management systems (Kearney, Li, Yu \& Braithwaite, 2019). ICAO's current requirement for AIR systems to be implemented from 2023 does not stipulate the use of eye-tracking technology. Failing to include this technology would arguably miss an opportunity for investigators to gain a better understanding of pilots' visual behaviours on the flight deck. This paper uses the case study of a rejected landing to illustrate the additional value that eye-tracking could bring to the accident investigation process.

\section{Background to requirements for AIR}

Although there are differing opinions amongst regulators, aircraft manufacturers, aircraft operators and pilots unions regarding the implementation of cockpit/airborne image recorders, ICAO require aircraft weighing over 27,000 kilograms to record all electronic displays and flight crews operating switches and selectors after 1st January 2023 (Costa, 2019; ICAO, 2018). The concept of installing AIR is to provide reliable evidence from an incident or accident which will permit investigators to assess crew reactions to aural/visual alerts and cockpit HCI to develop effective prevention strategies for aviation safety (Lik, Ates, \& Uzulmez, 2018).

\subsection{Current limitations of CVR and FDR in accident investigation}

Accident investigation reports demonstrate that CVR and FDR sometimes do not offer sufficient evidence to explain the contributing factors leading to an accident or incident, particularly when the crew perish in the event (Li \& Braithwaite, 2019). Taking the TransAsia Airways Flight GE235 as an example, the ATR 72-600 aircraft experienced a loss of control and crashed into a river (ASC, 2016). Through the information decoded from the FDR and CVR, it was quickly discovered that the flight crew had shut down the operative engine eventually causing a total loss of power (figure 1). However, why the pilot flying (PF) misidentified the problem and shut down the wrong engine, and why the error was not detected by the pilot monitoring (PM) remains unknown (Wang et al., 2017). Had additional evidence such as the visual parameters and scan patterns of the crew been recorded by using eye tracking as part of an AIR, investigators may have developed a more complete understanding of how the flight crew interacted with the automated systems.

Complexity of HCI renders it challenging to identify probable contributory factors leading to human-machine interaction-related incidents/accidents (Nandiganahalli, Lee, Hwang \& Yang, 2014). The installation of flight crew-machine interface recorders 
will offer insight into the significant role pilot's attention, decision-making, action and reactions with the automated system of modern aircraft influence aircraft operations ( $\mathrm{Li}$ et al., 2019). ICAO's favored approach to AIR systems is to position them so as to record the information which is available to the crew. Specifically it is proposed that the recording equipment shall not capture the head and shoulders of the flight crew while seated in their normal operating position (ICAO, 2018). To ensure the maximum contribution to accident investigation from the installation of AIR equipment there are certain parameters that must be captured such as the operation of all switches/selectors

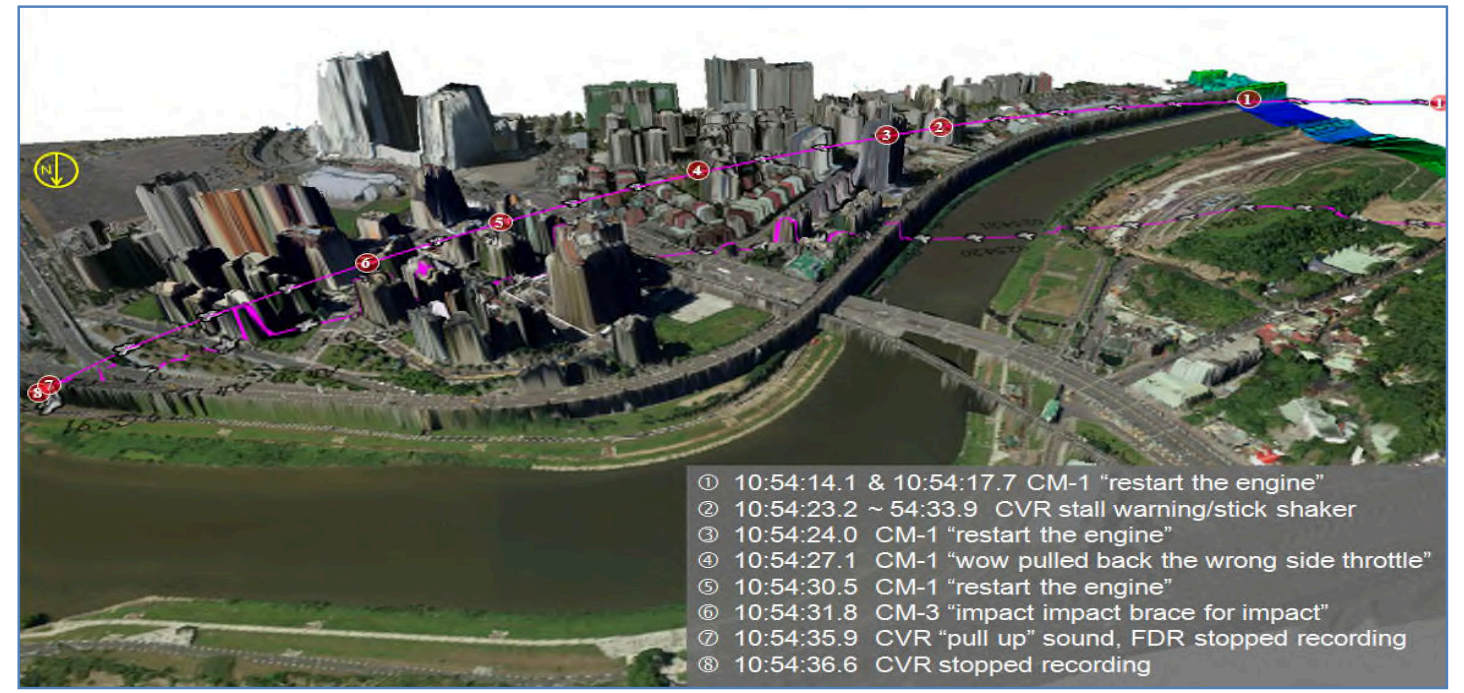

that will affect the operations/navigation of the aircraft; the primary flight and navigation displays; aircraft monitoring displays; engine indication displays; traffic, terrain and weather displays; crew alerting systems displays; stand-by-instruments; and if installed, electronic flight bag (EFB).

Figure 1. GE235 key events rendered on a fused satellite image, CVR and FDR

\subsection{The complicated nature of HCI in the flight deck}

A common feature of accident investigations where flight crew performance may have been a factor is an examination of HCI in the flight deck. Information processing by crew is often biased towards seeking evidence that confirms their prior beliefs and experiences and pattern matching (Hunt et al., 2016). Despite such biases being a pervasive feature of human behavior, the underlying causes remain unclear and this remains a large challenge when investigating HCI in the flight deck (Merritt, Heimbaugh, LaChapell, \& Lee, 2013). Understanding the nature of pilot decisionmaking has emerged from epidemiological approaches to aircraft accidents and incidents. Pilot interaction with automated systems in the flight deck was identified as a significant factor in precipitating aviation occurrences (Hunter, Martinussen, 
Wiggins, \& O'Hare, 2011). Many accounts of these HCI issues highlight the limitations of cognitive capacity in the flight deck, as pilots deal with complicated situations requiring enormous cognitive processing to solve the issue presented. Effective visual attention distributions in the flight deck is a fundamental requirement in achieving and maintaining SA (Prince \& Salas, 1998; Wang et al., 2017; Kearney \& Li, 2018). Eye tracking technology can provide detailed information regarding pilot's visual attention shifts and SA (figure 2). Situational assessment is used as a pre-cursor to generate a plausible course of action, and mental simulation to evaluate that course of action for risk management (Endsley, 2015). A significant number of investigation reports reveal that inappropriate decision-making related to $\mathrm{HCI}$ remains a relatively pervasive factor associated with aviation accidents (Fulton, Westcott \& Emery, 2009; ASC, 2018).

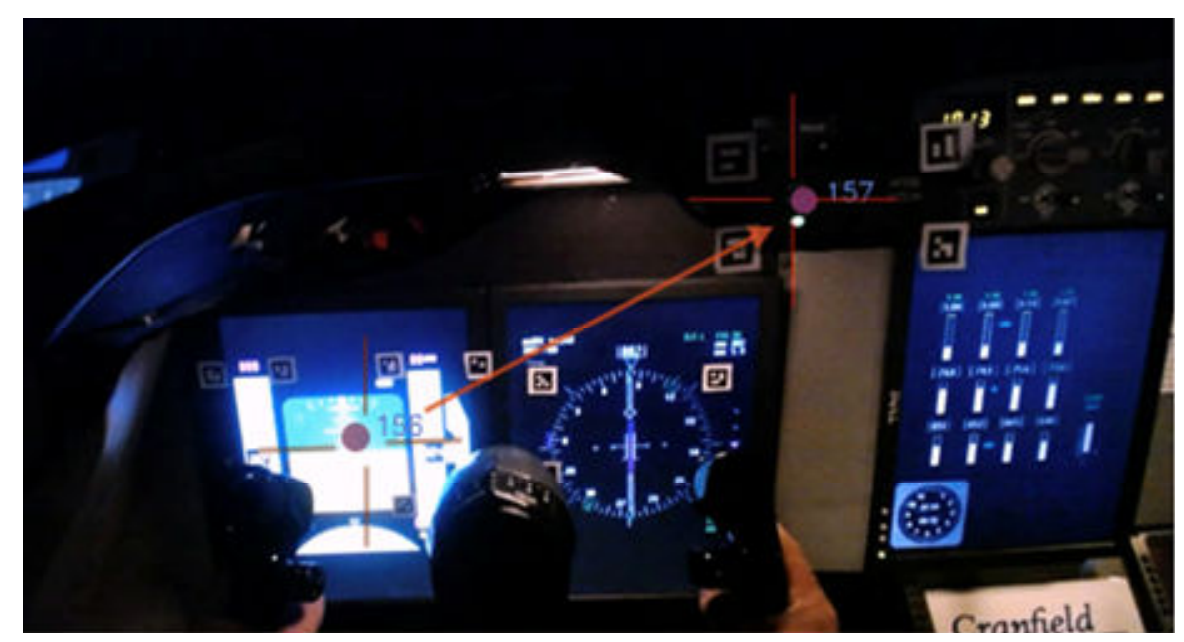

Figure 2. Pilot's attention shifts from Primary Flight Display (fixation-156) to Flight Mode Annunciator (fixation-157) due to mode changes recorded by eye tracker

\subsection{The growing need for AIR in the flight deck}

Commercial aircraft have become progressively more automated delivering benefits in operational efficiency and safety (Billings, 1991). However this automation has also created a number of operational complexities for pilots leading to safety concerns such as “automation-surprise" (Dekker, 2001; Dekker \& Hollnagel, 2004). Avionics systems on advanced flight decks contain a lot of instruments with many parameters being recorded by FDR. However, critical safety factors such as pilot responses to abnormal situations and decision-making, are not recorded by CVR or FDR. Thus far, the techniques involved in investigating human performance and HCI are limited to interviews; reviews of training records; and reviews of the flight profile based on FDR and CVR data to draw conclusions about the operational behaviours of the flight crew. 
The Air France Flight 447 accident which occurred in 2009 with the loss of 228 lives is an example of where the lack of evidence relating to the human-machine interface (HMI) led the investigation agency, the Bureau d'Enquêtes et d'Analyses (BEA), to report that the lack of cockpit image recorders hampered their understanding of the evolving situation which the crew faced. The aircraft was equipped with a FDR which collected far more parameters than the minimum requirements. However, evidence relating to pilots' actions and responses to unreliable airspeed indications; their visual scan patterns of the flight deck instruments; and the degradation of avionics systems were not available to accident investigators. This made it difficult to make recommendations about the HMI or associated crew training. Other investigations conducted by the US National Transportation Safety Board (NTSB) also found that FDR and CVR provide very limited information regarding crew's actions and HCI in the flight deck (NTSB, $2000 \& 2002$ ). The BEA subsequently recommended that ICAO require passenger transport flights be installed with flight crew-machine interface recording systems or AIR. However, without the ability to accurately track the eye movements of crew, such a system may not realize its full potential.

\subsection{Eye tracking provides complementary information to investigate $\mathrm{HCI}$}

Visual behavior provides an important source of evidence to investigate HCI issues related to pilot's attention distributions and SA in flight operations. Eye movements can be analyzed to explore the relationship between attention distribution among instruments and human performance in the flight deck (Ahlstrom \& Friedman-Berg, 2006, Peysakhovich, Lefrançois, Dehais, \& Causse, 2018). Developing AIR systems that include flight deck eye tracking devices may be an alternative scientific approach to record detailed information for accident investigation. Previous research demonstrated that eye tracking technology provides additional visualization parameters which are closely linked to human information processing and attention distributions (table 1). HCI issues leading to accidents have increased in aviation, representing a large gap between the functions of automation and pilot cognition (Li et al., 2019). How information is presented is significantly related to its readability, ease of interpretation, and accessibility, thus affecting pilot's attention distribution, perception, decisionmaking and safety of flight operations (Endsley, 2015).

Table 1. Eye tracking parameters related to cognitive process and HCI

\begin{tabular}{|l|l|l|}
\hline $\begin{array}{l}\text { Visual } \\
\text { Parameter }\end{array}$ & \multicolumn{1}{|c|}{ Definition } & \multicolumn{1}{|c|}{ Previous research } \\
\hline Gaze & $\begin{array}{l}\text { The fundamental framework of eye } \\
\text { movement }\end{array}$ & $\begin{array}{l}\text { Gaze might be the precursor of fixation and } \\
\text { enables prompt processing peripheral } \\
\text { information (Yu et al., 2014) }\end{array}$ \\
\hline
\end{tabular}




\begin{tabular}{|l|l|l|}
\hline $\begin{array}{l}\text { Fixation } \\
\text { counts }\end{array}$ & $\begin{array}{l}\text { Pauses over informative regions of } \\
\text { interest }\end{array}$ & $\begin{array}{l}\text { Monitoring performance during detection } \\
\text { phases (Hasse, Grasshoff \& Bruder, 2012) }\end{array}$ \\
\hline $\begin{array}{l}\text { Fixation } \\
\text { duration }\end{array}$ & $\begin{array}{l}\text { The sum of all durations on fixating } \\
\text { an AOI }\end{array}$ & $\begin{array}{l}\text { Difficulty and importance of AOIs (Kotval } \\
\text { and Goldberg, 1998; Dehais et al., 2017) }\end{array}$ \\
\hline Pupil size & Area of pupil dilation & $\begin{array}{l}\text { Emotion, arousal, stress, pain, or cognitive } \\
\text { load (Wang, 2010; Li et al., 2019) }\end{array}$ \\
\hline Saccades & Rapid movements between fixations & $\begin{array}{l}\text { Direction of a shift of attention } \\
\text { (Henderson, 2003; Kowler, 2011; Salvucci } \\
\text { \& Goldberg, 2000) }\end{array}$ \\
\hline $\begin{array}{l}\text { Saccade } \\
\text { duration }\end{array}$ & $\begin{array}{l}\text { How much time to make a saccade } \\
\text { between fixations }\end{array}$ & $\begin{array}{l}\text { More workload, less saccade duration. } \\
\text { (Rognin et al., 2004; Glaholt \& Reingold, } \\
\text { 2011) }\end{array}$ \\
\hline $\begin{array}{l}\text { Saccade } \\
\text { velocity }\end{array}$ & $\begin{array}{l}\text { How fast the eyes move between } \\
\text { fixations }\end{array}$ & $\begin{array}{l}\text { Slower saccade velocity as scanning on the } \\
\text { related cues (McColemana \& Blair, 2013; } \\
\text { Li et al., 2016). }\end{array}$ \\
\hline
\end{tabular}

There are limitations to applied eye tracking technology in the flight deck. Pilots may see messages on an instrument without directly fixating on them based on peripheral vision. Eye trackers are not able to capture peripheral vision which is significantly related to where the fovea fixate (Ross, 2009). Furthermore, pilot fixations do not necessarily equal attention or understanding ( $\mathrm{Li}$ et al, 2019). Visual behaviours show only fixation points where the fovea stops to take information. Fixations alone do not explain the higher-level processes of comprehension and decision-making. In other words, recording a pilot's eyes fixating on messages from displays does not necessarily mean the pilot is consciously paying attention to that element or comprehending it (Johansen \& Hansen, 2006). This is why eye tracking data has little meaning by itself. Careful observation of pilot's actions coupled with discussion by professional instructors is necessary to try and understand the pilot's mental processes in the flight deck. Therefore, eye tracking can provide complementary data to aid in the accident investigation but is insufficient as an investigation tool in isolation (Ross, 2009).

\section{Case study of investigating A330-300 rejected landing}

The approach of this investigation included interviews, observations, document review, exploring artifacts, decoding CVR and FDR to collect data and generate a report. The purpose of this research is to examine the current challenges in accident investigation as a result of the lack of detailed recorded information related to HCI and human performance in the flight deck. 


\subsection{Background of occurrence on rejected landing}

On 1st October 2016, an Airbus A330-300 aircraft (CI-704) was on a scheduled international flight from Manila (RPLL) to Taipei (RCTP). At 1927 local time, the aircraft experienced a tail strike while the flight crew were performing a rejected landing on runway 23R of Taoyuan Airport. The aircraft suffered structural damage to the tail section as well as abrasions to the lower skin of the rear fuselage (figure 3 ). None of the 137 people on board were injured; however, the affected runway was closed in order to complete an inspection of the surface and facilitate the removal of debris (ASC, 2018).

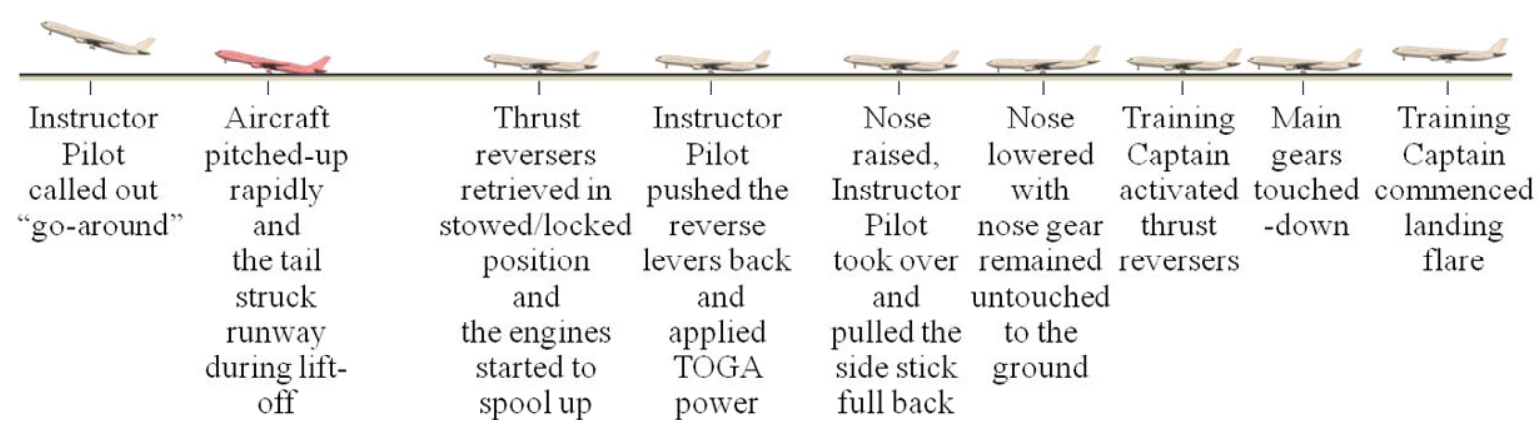

Figure 3. Sequence of the rejected landing tail-strike occurrence initiated by instructor pilots

\subsection{Description of pilots' operational behaviours in the flight deck}

The accident occurred during the final stage of landing during main-wheel touch-down and while the nose-wheel was still in the air. The instructor pilot discovered that instead of pitching down gradually, the aircraft's nose was instead, to his surprise, raised. This situation made him feel that the aircraft would become airborne again (dotted circle at Pitch Angle section on Figure 4). His first impression was the Training Captain's performance matched comments made by other instructors in his training reports indicating a tendency to land with a nose up attitude after main gear touch-down. Based on the instructor pilot had a safety concern about a pitch-up situation and took control of the flight and decided to reject the landing by applying Takeoff/Go-around (TOGA) thrust (dotted circles at the MAN TOGA section on Figure 4). However, the instructor pilot was not aware that the thrust reversers had already been activated by the Training Captain so he could not advance the thrust levers as they were restricted by the interlock. The Instructor Pilot was concerned that the aircraft would not be able to land within 3,000 ft from the runway threshold; a company operating policy. Whilst the airline's operational procedures also specified that crews must conduct a full-stop 
landing if reverse thrust had been activated, considering the uncertainty of available runway, the Instructor Pilot didn't amend his decision about executing a go-around even after realizing the thrust reverser activation. (11:27:22 on figure 4).

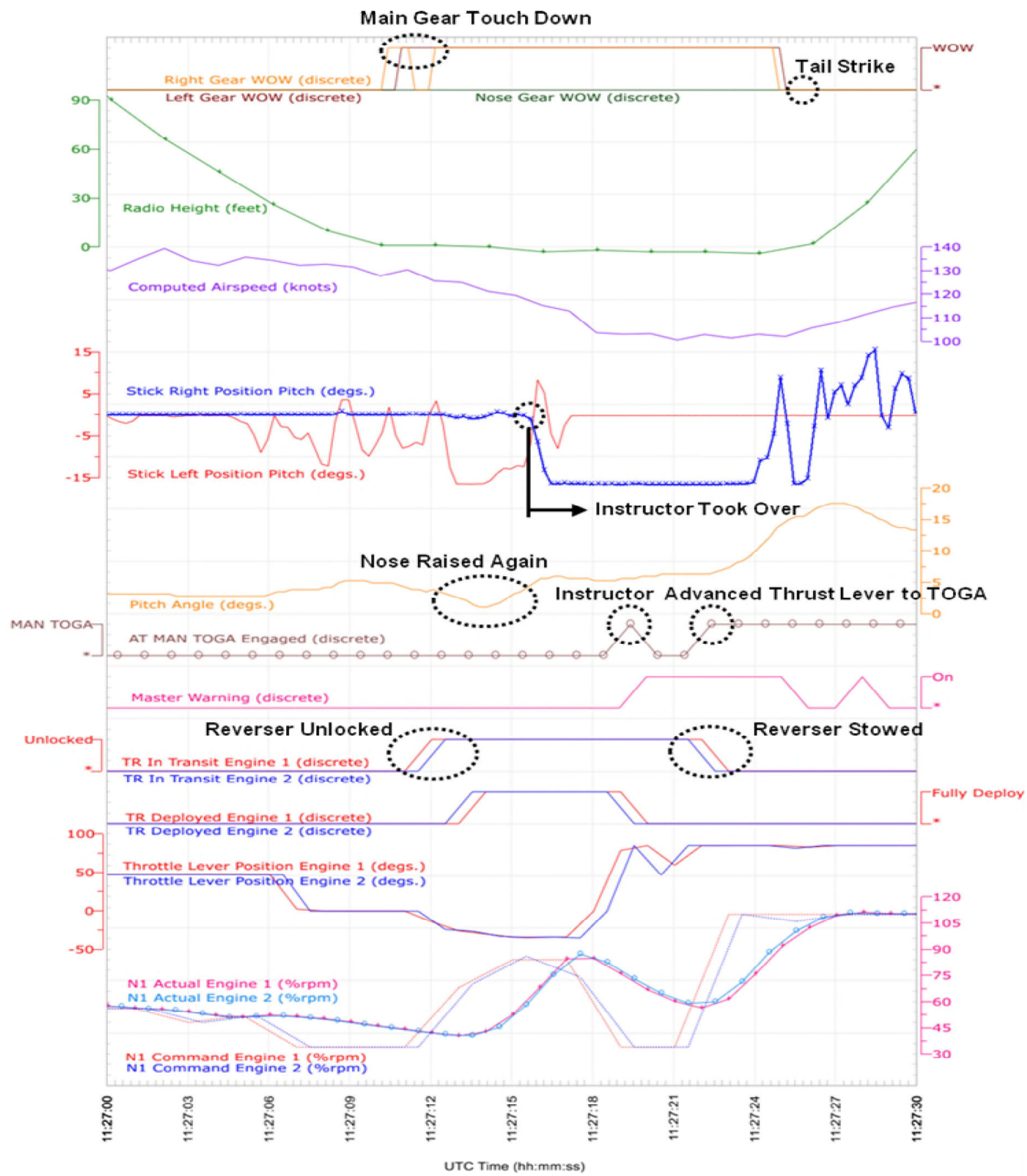

Figure 4. The FDR parameters and timestamp on human-computer interactions during rejected landing of A330-300

\subsection{Analyzing FDR parameters related to HCI on rejected landing}


A rejected landing is defined as a go-around maneuver initiated after a positive decision by the flight crew to continue to a landing below the minimum decision height for a particular approach. The rejected landing procedure is identical to the go-around procedure: Once the decision is made to reject the landing, the flight crew must be committed to proceed with the go-around maneuver applying TOGA thrust, they should not be tempted to retard the thrust levers in an attempt to resume the landing. Reversing a go-around decision is generally observed when the decision to abort the landing and to initiate a go-around is taken by the PF but is overridden by the other crew members (dotted circles at the Unlocked section on Figure 4). Although a rare occurrence, a rejected landing is a challenging maneuver conducted under time pressure, generally as an unanticipated and therefore unprepared situation.

There are HCI issues relating to the instructor pilot's decision-making in this occurrence. As the pilot in command, the instructor pilot was responsible for the safe operation of the aircraft. Therefore, he is authorized to make the final decision regarding all aircraft operating situations, including executing a rejected landing without hesitation when a safe landing cannot be assured. In the occurrence flight, as the instructor pilot made his decision to reject the landing, he was supposed to commit to the go-around maneuver by promptly applying TOGA thrust, and not be tempted to resume the landing in compliance with the afore mentioned procedures. However, at the time he tried to advance the thrust levers he was unable as the thrust reversers had already been activated by the Training Captain (dotted circle at Reverser Unlocked on figure 4). At this point, the airline's procedure required that the rejected landing must be aborted, and a full stop landing shall be completed.

\subsection{Limitations of investigating HCI on the flight deck}

Human beings are more likely to apply information that confirms their expectations. This information processing bias tends to occur in ambiguous circumstances (Merritt et al., 2013). The investigation of this rejected landing revealed the probable causes were related to attention distribution, SA, cross-checking, crew communication, decision-making, non-compliance with the standard operating procedures (SOPs), and confirmation bias. The data retrieved from the FDR (figure 4) validated the instructor's explanation of how the occurrence of the tail strike occurred and how it reflected the instructor's operational behavior. However, the data from the FDR and CVR did not explain why the decision made sense to the instructor pilot at that moment in time. The CVR and FDR data demonstrated the instructor's non-compliance with SOPs which may imply a lack of operational skill and insufficient cross-checking. Investigators only know what pilots have done or not done and said or not said based on crew interviews 
and CVR/FDR data, there is a lack of direct evidence related to pilot's attention, SA and decision-making. The inductive leap made by investigators may seem plausible based on the investigators' professional experience, but it can't be proven due to lack of direct evidence. For example, there is no way to prove the existence of the Instructor Pilot's confirmation bias based on his reading of the Training Captains historic operational behaviors during approach and landing in the training records Accident investigation inherently requires speculation, assumptions, hypotheses and interpretations. The data from the FDR and CVR may not be sufficient to support or quash such speculations and interviews with witnesses are not always accurate or reliable. Therefore, it is necessary to acquire visual information from AIR, which can be applied to investigate human-computer interactions and pilot's cognitive processes in the flight deck.

Accident investigators replicated this rejected landing scenario using an A330 Full Flight Simulator and two Instructor Pilots. These simulator trials provided high fidelity information on the critical indicators and HCI issues in flight operations during a rejected landing. Therefore, investigators were able to explore effective responses and attentional distributions in the flight deck to make recommendations. It was observed that, at the time of the tail strike occurrence there was lots of information available which must be assimilated by the Instructor Pilot, such as the pitch attitude; air speed on primary flight display (PFD); the status of thrust reversers on the systems display (SD); warning messages on engine/warning display (EWD); the position of the thrust reverser levers; as well as the view outside the cockpit window to determine the adequacy of the aircraft attitude and stopping distance. The volume of information was significantly more compared to a normal landing operation. Simulator trials can facilitate the development of effective accident prevention strategies for rejected landing and go-arounds in the future.

\subsection{Complementary visual parameters facilitating A330-300 investigation}

In this A330-300 accident investigation, the Aviation Safety Council found that FDR data was within normal ranges before the tail strike (ASC, 2018). It became an important factor for the investigators who were attempting to understand why the instructor pilot made the decision to reject the landing, assume command and advance the thrust reverse levers and apply TOGA power. The synchronization of FDR, CVR transcript and pilots' operational status during the rejected landing is shown in figure 5. Due to the limited data recorded in the FDR and CVR, it is impossible to recreate the pilots' attention distribution and SA during the approach and tail-strike occurrence. Post-accident on-scene measurement revealed that the point at which the aircraft lifted 
off left up to $7,700 \mathrm{ft}$ remaining to stop. Diverse opinions were expressed throughout the investigation regarding the decision-making of the Instructor Pilot and the necessity of his taking control of the flight. Accident and incident analyses have revealed that goaround procedures are often imperfectly performed because of complexity and time pressure. This investigation clearly demonstrated that complicated HCI took place within the flight deck after the thrust reversers were deployed. In view of the associated risks of go-around and rejected landing operational procedures and training manuals all contain one specific proviso that "in any case, if reverse thrust has been applied, a full stop landing must be made". In a simulator study, Dehais et al., (2017) demonstrated that an eye tracker is a valuable tool for the explicit training of attention allocation during go-around to enhance aviation safety.

An incident or accident sequence is typically made up of individual controversial decision points that can then be scrutinized to develop accident prevention strategies (Li et al., 2014). However, detailed information related to the human operators' visual parameters, operational behaviors, and SA are rarely available to investigators. Based on figure 5, investigators can understand what happened by synchronizing FDR, CVR transcript and pilots' operational status during the rejected landing / tail-strike occurrence. However, this data does not explain why and how the event developed. With the installation an eye tracking device to record pilot's visual parameters, it would be possible to reproduce pilot's scan patterns and operational behaviours. The investigation report concluded that the attention allocation and SA of the Instructor Pilot were probably affected by his confirmation bias, in that he focused too much on the aircraft's attitude but neglected to monitor critical information during landing. Without eye tracking data there is no evidence to corroborate the Instructor Pilot's explanation regarding taking control of the flight during the rejected landing. In spite of observations in simulation trials which were conducted during the investigation, the conclusions were still based on the investigators' subjective judgment rather than a compelling evidence source. 


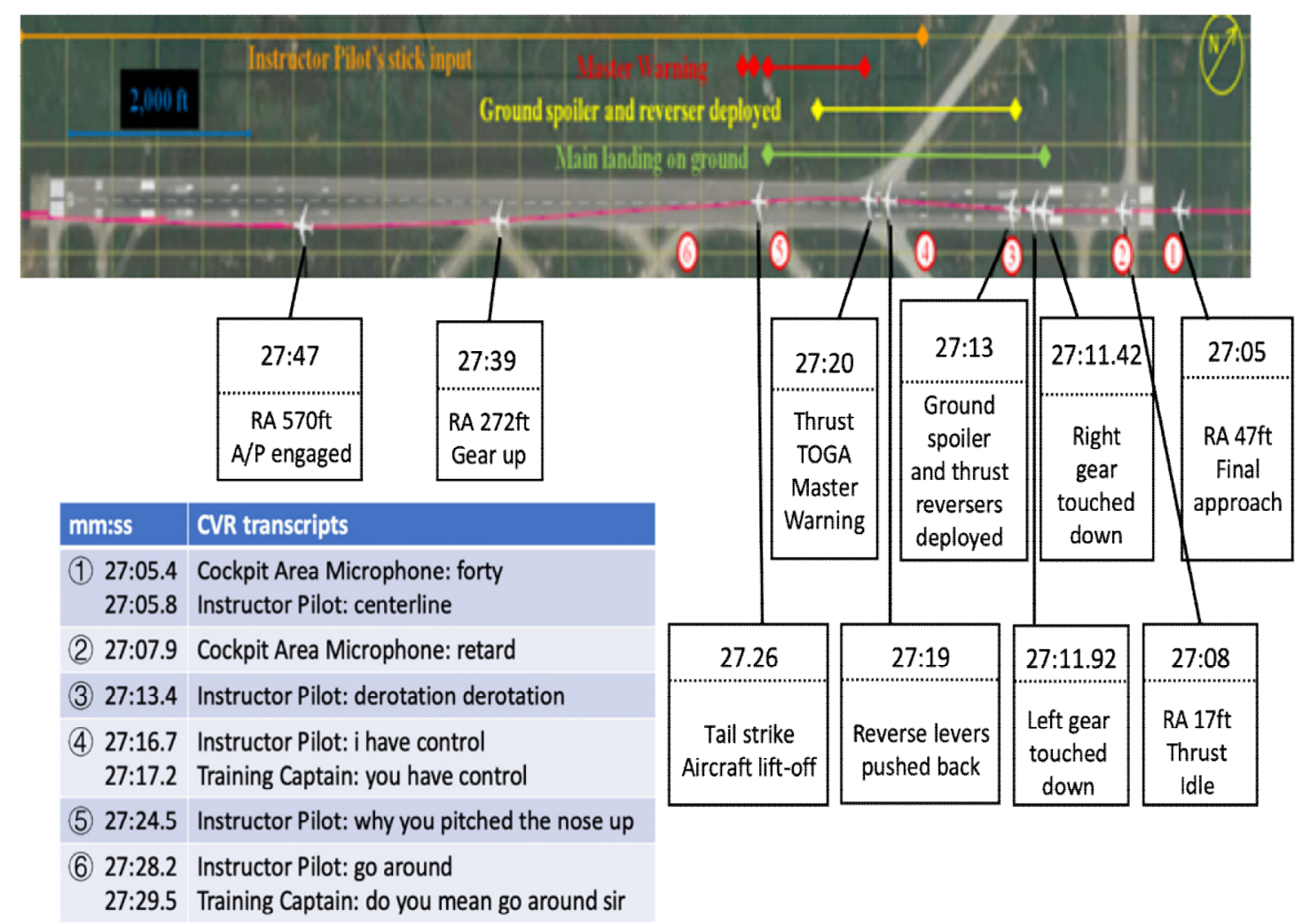

Figure 5. The synchronization of FDR, CVR transcript and pilots' operational status during rejected landing tail-strike occurrence

\section{General Discussion}

Advanced flight decks lead to new safety concerns such as mode confusion and dysfunctional interactions between the pilots and the automation (Lee, Hwang \& Leiden, 2015). In many aviation accidents, investigators have identified improper HCI as a source of incident or accident. However, due to complexity of a pilot's decisionmaking process, it is challenging to identify all points of interaction between the pilot and automation (Nandiganahalli, et al., 2014; Vaidya, Lee \& Hwang, 2016). Various parameters of the automation and avionics systems such as autopilot, flight management system, primary flight display, navigation displays, engine indication, crew alerting system and communications can be recorded by conventional FDR and CVR. Following an accident, the investigators will extract the FDR and CVR data to generate a hypothesis of the probable causes of the events. However, as the A330-300 example demonstrates, there is currently no reliable way of capturing evidence regarding the operational behaviours of pilots and HCI. This makes it difficult to make definitive recommendations regarding crew performance or the design of procedures or the flight deck. 


\subsection{AIR as a facilitator accident investigations and prevention}

Proposals on installing commercial aircraft with AIR have been discussed within ICAO since 1995. Repeatedly, proposals for AIR have been rejected by pilots' unions due to their concerns about confidentiality. However, FDR and CVR data does not offer satisfactory information to explain pilot's attention and operational behaviours in the flight deck. For the past 25 years ICAO has consistently recommended that AIR be among the standard equipment on commercial flights and it now requires that newly designed aircraft embrace cockpit image recorders as standard equipment from 2023 (ICAO, 2018; Lik et al., 2018). The current absence of these recorders means that air accident investigators will continue to have difficulty in assessing what information was available to flight crew and what information flight crew were using during incidents and accidents. CVRs and FDRs do not always offer investigators enough information to determine accident contributing (ICAO, 2018). Airborne image recorders can provide detailed information to support the analysis of pilot's behaviors, the action taken and the consequences, though not necessarily making it possible to fully understand pilots' cognitive process. The availability of AIRs would permit investigators produce better reports with more data and analysis, thereby increasing public and industry trust in respect of the recommendations formed (ICAO, 2016). Furthermore, accident investigators can have a much clearer picture of what factors contributed to an occurrence if a cockpit image recorder could provide the pilot's visual parameters.

\subsection{Benefits of Integrated visual parameters into AIR}

The installation of AIR on the flight deck would enhance accident investigators' understanding of the elements that acted as triggers to an accident including $\mathrm{HCI}$ issues between PF and PM during their cross-check. In order to explain pilot's behavior in relation to occurrences, there are several human factors challenges during the investigation processes. Investigators cannot make conclusions solely based on theories and hypotheses. Without evidence of the link between the crews' actions and the aircraft's flight parameters, an investigation report will be published without an explanation of WHY. Current FDR and CVR are unable to provide enough data for HCI and pilot's cognitive processing information, the airborne image recorder can provide supplemental visual data for investigators. However, there is a better solution to provide valuable information to investigators; by integrating eye tracking technology with flight crew-machine interface recorders the system could precisely identify pilot's attention distribution, scan patterns, SA, perceived workload and human-computer interactions (left-hand side on figure 6) compared with the image recorded by crew- 
machine interface recorder (right-hand side on figure 6).

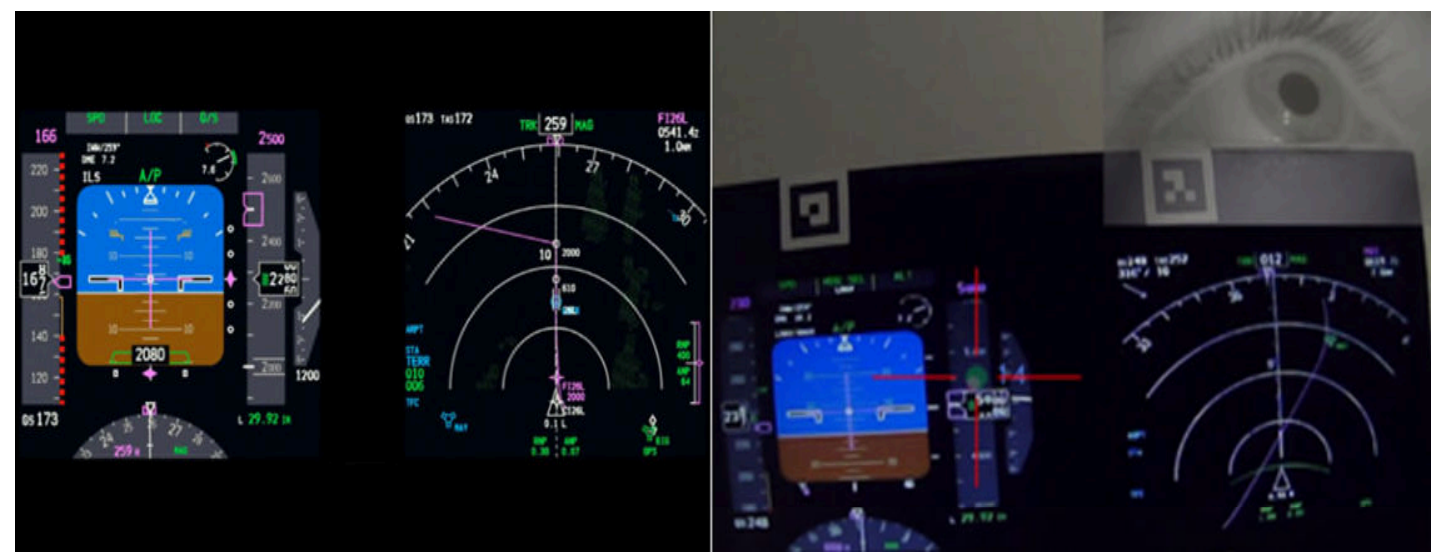

Figure 6. The images of PFD and ND captured by cockpit image recorder (left) versus pilot's fixations on the PFD with pupil dilation taken by eye tracker (right) providing specific information related to Human-Computer Interactions in flight operations

Visual attention can offer deep insights into HCI in the flight deck. AIR with eye tracking provides valuable data to better understand pilot's performance (Dehais et al., 2017). Eye trackers can provide the opportunity to investigate the relationship between pilot's attention shifts and cognitive processing during flight operations (Ahlstrom \& Friedman-Berg, 2006). Pupil dilation can be used for assessing a pilot's perceived workload and cognitive process based on physiological parameters (Ayaz et al., 2012; Li et al., 2016). Visual behaviors are automatic responses which may be linked to pilots' decision-making (Kuo, Hsu, \& Day, 2009). AIR integrated with eye tracker can record different aspects of pilot's ocular behavior, such as the number of fixations, dwell time, and the dilation of pupil across the various cockpit displays. The lack of this information in the A330-300 tail strike as a result of a rejected landing results in the absence of crucial information to further enhance safety and crew training. Eye tracking technology has proved effective at detecting cognitive states, fatigue, attentional tunneling and automation surprise (McKinley, McIntire, Schmidt, Repperger, \& Caldwell, 2011; Régis et al., 2014). Furthermore, eye tracker will not breach pilots' privacy concerns compared to the cockpit video recorder. The eye tracker is simply to monitor pilot's monitoring of the aircraft systems and state. There is considerable research available demonstrating that integrated eye tracking devices in flight simulators can significantly improve pilot's training, and facilitate incident/accident investigation (Van de Merwe, Van Dijk, \& Zon, 2012; Peysakhovich et al., 2018). 


\section{Conclusions and Recommendations}

The value that FDRs and CVRs provide to accident investigation is not in question, however FDR and CVR data has limitations in exploring human-computer interactions. An AIR system that includes eye tracking offers complementary visual information to investigate pilots' cognitive processes on the flight deck. This can help fill in the gaps of FDR and CVR data in regarding flight crew interactions and HCI. AIR integrated with an eye tracker is a tool which could also assist airlines to improve pilot's monitoring performance. Furthermore, the inclusion of an eye tracker does not breach pilots' privacy as it tracks eye movement only rather than facial expressions. There are some research limitations due to regulation and certification requirement for equipment on the flight deck. Any new device/sensor must be certified and approved by the appropriate civil aviation authority before installation in the cockpit, this was beyond the scope of this research paper. We can only conduct trials of rejected landing scenarios using a flight simulator. There is no empirical eye tracking data available to be compared with CVR/FDR data in the real-world operations. However, as authors we wished to prompt a discussion and consideration of the deployment, application and certification of eye tracking technology on the flight deck. We believe that the aviation industry could reap benefits from the addition of this technology as it can enhance both accident investigation and pilots' training in the future.

\section{Acknowledgements}

This Research was supported by National Science Council and Aviation Safety Council ((NSC101-2623-E-606-006-D; ASC 105-3114-Y-707-002). The authors would like to express special thanks to the accident investigators in the Aviation Safety Council, and all the pilots and aviation safety experts who provided their knowledge and challenging comments to this research. Their support and enthusiasm were invaluable in facilitating the authors' research efforts.

\section{References}

Ahlstrom, U., \& Friedman-Berg, F. J. (2006). Using eye movement activity as a correlate of cognitive workload. International Journal of Industrial Ergonomics, 36(7), 623-636. doi:10.1016/j.ergon.2006.04.002

Aviation Safety Council (2016). Aviation Occurrence Report (Report No. ASC-AOR16-06-001).

Retrieved from

Taipei,

Taiwan: https://www.asc.gov.tw/upload/acd_att/ASC-AOR-16-06-001 CH.pdf 
Aviation Safety Council (2018). Aviation Occurrence Report of CI-704 (Report No. ASC-FRP-18-01-002). Retrieved from Taipei, Taiwan: https://www.asc.gov.tw/upload/acd_att/ASC-AOR-16-06-001 CH.pdf

Ayaz, H., Shewokis, P. A., Bunce, S., Izzetoglu, K., Willems, B., \& Onaral, B. (2012). Optical brain monitoring for operator training and mental workload assessment. Neuroimage, 59(1), 36-47. doi:10.1016/j.neuroimage.2011.06.023

Bureau d'Enquêtes et d'Analyses (2012). Final report On the accident on 1st June 2009 to the Airbus A330-203 registered F-GZCP operated by Air France flight AF 447 Rio de Janeiro - Paris. Retrieved from Paris, France: https://en.wikipedia.org/wiki/Air_France_Flight_447 CITEREFBEA_final_French2012

Billings, C. E. (1991). Human-centered aircraft automation: A concept and guidelines. Retrieved from NASA Ames Research Center, Moffett Field, CA, United States: https://ntrs.nasa.gov/archive/nasa/casi.ntrs.nasa.gov/19910022821.pdf

Costa, M. (2019). New ICAO Initiatives on Accident Investigation. Paper presented at the fourth International Accident Investigation Forum, Changi Airport, Singapore.

Dehais, F., Behrend, J., Peysakhovich, V., Causse, M., \& Wickens, C. D. (2017). Pilot flying and pilot monitoring's aircraft state awareness during go-around execution in aviation: A behavioral and eye tracking study. The International Journal of Aerospace Psychology, 27(1-2), 15-28. doi:10.1080/10508414.2017.1366269

Dekker, S. (2001). The disembodiment of data in the analysis of human factors accidents. Human Factors and Aerospace Safety, 1(1), 39-57.

Dekker, S., \& Hollnagel, E. (2004). Human factors and folk models. Cognition, Technology and Work, 6(2), 79-86. doi:10.1007/s10111-003-0136-9

Endsley, M. R. (2015). Situation awareness misconceptions and misunderstandings. Journal of Cognitive Engineering and Decision Making, 9(1), 4-32. doi:10.1177/1555343415572631

Elling, S., Lentz, L., \& de Jong, M. D. T. (2012). Combining concurrent think-aloud protocols and eye-tracking observations: An analysis of verbalizations and silences. IEEE Transactions on Professional Communication, 55(3), 206-220. doi:10.1109/tpc.2012.2206190

Federal Aviation Administration (1991). Aeronautical Decision-making (Report no. Advisory Circular 60-22). Retrieved from US Department of Transport, Washington: https://www.faa.gov/documentLibrary/media/Advisory_Circular/AC_60-22.pdf

Fulton, N. L., Westcott, M. \& Emery, S. (2009). Decision support for risk assessment of mid-air collisions via population-based measures. Transportation Research Part A: Policy and Practice, 43(2), 150-169. doi:10.1016/j.tra.2008.08.003 
Galfano, G., Dalmaso, M., Marzoli, D., Pavan, G., Coricelli, C., \& Castelli, L. (2012). Eye gaze cannot be ignored (but neither can arrows). The Quarterly Journal of $\begin{array}{lll}\text { Experimental } \quad \text { Psychology, } & \text { 65(10), }\end{array}$ doi:10.1080/17470218.2012.663765

Glaholt, M. G., \& Reingold, E. M. (2011). Eye movement monitoring as a process tracing methodology in decision making research. Journal of Neuroscience, Psychology, and Economics, 4(2), 125. doi:10.1037/a0020692

Hasse, C., Grasshoff, D., \& Bruder, C. (2012, March). How to measure monitoring performance of pilots and air traffic controllers. In Proceedings of the Symposium on Eye Tracking Research and Applications (pp. 409-412). Santa Barbara, CA: ACM. doi:10.1145/2168556.2168649

Henderson, J. M. (2003). Human gaze control during real-world scene perception. Trends in Cognitive Sciences, 7(11), 498-504. doi:10.1016/j.tics.2003.09.006

Hunt, L. T., Rutledge, R. B., Malalasekera, W. N., Kennerley, S. W., \& Dolan, R. J. (2016). Approach-induced biases in human information sampling. PLoS biology, 14(11), e2000638. doi:10.1371/journal.pbio.2000638

Hunter, D. R., Martinussen, M., Wiggins, M., \& O'Hare, D. (2011). Situational and personal characteristics associated with adverse weather encounters by pilots. Accident Analysis and Prevention, 43(1), 176-186. doi:10.1016/j.aap.2010.08.007

International Civil Aviation Organization (2010). Annex 6 to the Convention on International Civil Aviation: Operation of Aircraft. Retrieved from Montreal, Canada:

https://www.icao.int/safety/fatiguemanagement/FRMS\%20Tools/Amendment\% $2037 \% 20$ for $\% 20$ FRMS $\% 20$ SARPS $\% 20 \% 28$ en $\% 29$.pdf

International Civil Aviation Organization (2013). Manual of Evidence-based Training (Doc 9995 AN/497). Retrieved from Montreal, Canada: https://icao.int/SAM/Documents/2014-AQP/EBT ICAO Manual Doc 9995.en.pdf International Civil Aviation Organization (2016). Technical Commission: Aviation Safety and Air Navigation Standardization, Airborne image recorders (A39WP/307).

Retrieved

from https://www.icao.int/Meetings/a39/Documents/WP/wp_307_en.pdf

International Civil Aviation Organization (2018). Airborne image recordings and flight data recorder parameters lists. Retrieved from https://www.icao.int/safety/Documents/2018 Annex Amendments.pdf

Jensen, R. S., \& Benel, R. A. (1977). Judgment evaluation and instruction in civil pilot training, Final Report FAA-RD-78-24 National Technical Information Service. Retrieved from Springfield, VA, USA: https://trid.trb.org/view/75609 
Johansen, S. A., \& Hansen, J. P. (2006, April). Do we need eye trackers to tell where people look? In Proceedings of the 2006 CHI Conference on Human Factors in Computing Systems (pp. 923-928). New York, NY: ACM. doi:10.1145/1125451.1125630

Kearney, P., \& Li, W. C. (2018). Multiple remote tower for Single European Sky: The evolution from initial operational concept to regulatory approved implementation. Transportation Research Part A: Policy and Practice, 116, 15-30. doi:10.1016/j.tra.2018.06.005

Kearney, P., Li, W. C., Yu, C. S., \& Braithwaite, G. (2019). The impact of alerting designs on air traffic controller's eye movement patterns and situation awareness. Ergonomics, 62(2), 305-318. doi:10.1080/00140139.2018.1493151

Kotval, X. P., \& Goldberg, J. H. (1998, October). Eye movements and interface component grouping: An evaluation method. In Proceedings of the Human Factors and Ergonomics Society Annual Meeting (Vol. 42, No. 5, pp. 486-490). Los Angeles, CA: SAGE Publications. doi:10.1177/154193129804200509

Kowler, E. (2011). Eye movements: The past 25 years. Vision research, 51(13), 14571483. doi: /10.1016/j.visres.2010.12.014

Kuo, F. Y., Hsu, C. W., \& Day, R. F. (2009). An exploratory study of cognitive effort involved in decision under Framing - an application of the eye-tracking technology. Decision Support Systems, 48(1), 81-91. doi:10.1016/j.dss.2009.06.011

Lee, S., Hwang, I., \& Leiden, K. (2015). Intent inference-based flight-deck humanautomation mode-confusion detection. Journal of Aerospace Information Systems, 12(8), 503-518. doi: 10.2514/1.I010331

Li, W. C., \& Braithwaite, G. (2019). Enhancing Accident Investigation Capability and Human Resilience through Emerging Technology for Digital Aviation. Paper presented at the fourth International Accident Investigation Forum, Changi Airport, Singapore.

Li, W. C., Li, L. W., Harris, D., \& Hsu, Y. L. (2014). The Application of Aeronautical Decision-making Support Systems for Improving Pilots. Journal of Aeronautics, Astronautics and Aviation, 46(2), 114-123. doi:10.6125/14-0324-789

Li, W. C., Yu, C. S., Braithwaite, G., \& Greaves, M. (2016). Pilots' attention distributions between chasing a moving target and a stationary target. Aerospace medicine and human performance, 87(12), 989-995. doi:10.3357/AMHP.4617.2016

Li, W. C., Zhang, J. Y., Le Minh, T., Cao, J. Q., \& Wang, L. (2019). Visual scan patterns reflect to human-computer interactions on processing different types of messages in the flight deck. International Journal of Industrial Ergonomics, 72, 
54-60. doi:10.1016/j.ergon.2019.04.003

Lik, H., Ates, S., \& Uzulmez, M. (2018). Deadly preference between flight safety and private life protection. Journal of Aerospace Engineering. doi:10.4172/21689792-C2-026

McColemana, C. M., \& Blair, M. R. (2013). The relationship between saccade velocity, fixation duration, and salience in category learning. Visual Cognition, 21(6), 701703. doi:10.1080/13506285.2013.844965

McKinley, R. A., McIntire, L. K., Schmidt, R., Repperger, D. W., \& Caldwell, J. A. (2011). Evaluation of eye metrics as a detector of fatigue. Human Factors, 53(4), 403-414. doi:10.1177/0018720811411297

Merritt, S. M., Heimbaugh, H., LaChapell, J., \& Lee, D. (2013). I trust it, but I don't know why: Effects of implicit attitudes toward automation on trust in an automated system. Human factors, 55(3), 520-534. doi:10.1177/0018720812465081

Nandiganahalli, J. S., Lee, S., Hwang, I., \& Yang, B. J. (2014). User interface validation using mode confusion detection. Paper presented at AIAA Modeling and Simulation Technologies Conference, Atlanta, GA, USA. doi:10.2514/6.2014-2349

National Transportation Safety Board (2000). Aircraft Accident Report, SilkAir Flight MI185, Boeing B737-3009V-TRF, Musi River, Palembang, Indonesia, December 19, 1997. Retrieved from Department of Communications, Republic of Indonesia: Jakarta:

http://dms.ntsbgov/pubdms/search/document.cfm?docID=377242\&docketID=15 $358 \&$ mkey $=11051$

National Transportation Safety Board (2002). EgyptAir Flight 990, Boeing 767-366ER. SU-GAP 60 Miles South of Nantucket, Massachusetts. October 31, 1999, AAB02/01 Retrieved from Washington, DC: National Transportation Safety Board: http://www.ntsb.gov/investigations/AccidentReports/Reports/AAB0201.pdf

National Transportation Safety Board (2015). Safety Recommendation A-15-007: flight data recorder be retrofitted with a crash-protected cockpit image recording system compliant with Technical Standard Order TSO-C176a. Retrieved from Washington, D.C.: https://www.ntsb.gov/safety/safety-recs/recletters/A-15-001008.pdf

Orasanu, J., \& Connolly, T. (1993). The reinvention of decision making. In Decision making in action: Models and methods. (pp. 3-20). Westport, CT, US: Ablex Publishing.

Peysakhovich, V., Lefrançois, O., Dehais, F., \& Causse, M. (2018). The neuroergonomics of aircraft cockpits: the four stages of eye-tracking integration 
to enhance flight safety. Safety, 4(1), 8. doi:10.3390/safety4010008

Prince, C., \& Salas, E. (1998). Situation assessment for routine flight and decision making. International Journal of Cognitive Ergonomics, 1(4), 315-324.

Régis, N., Dehais, F., Rachelson, E., Thooris, C., Pizziol, S., Causse, M., \& Tessier, C. (2014). Formal Detection of Attentional Tunneling in Human OperatorAutomation Interactions. IEEE Transactions on Human-Machine Systems, 44(3), 326-336. doi:10.1109/THMS.2014.2307258

Robinski, M., \& Stein, M. (2013). Tracking visual scanning techniques in training simulation for helicopter landing. Journal of Eye Movement Research, 6(2):3, 117. doi:10.16910/jemr.6.2.3

Rognin, L., Grimaud, I., Hoffman, E., \& Zeghal, K. (2004). Assessing the impact of a new instruction on air traffic controller monitoring tasks. Retrieved from https://www.academia.edu/download/49730986/Assessing_the_Impact_of_a_Ne w_Instructio20161019-26636-nl7mju.pdf

Ross, J. (2009). Eyetracking: Is it worth it? Retrieved October 19, 2009, from http://www. uxmatters. com/mt/archives/2009/10/eyetracking-is-it-worth-it. php

Salvucci, D. D., \& Anderson, J. R. (1998). Tracing eye movement protocols with cognitive process models. Paper presented at the Twentieth Annual Conference of the Cognitive Science Society, Hillsdale, NJ.

Salvucci, D. D., \& Goldberg, J. H. (2000, November). Identifying fixations and saccades in eye-tracking protocols. In Proceedings of the 2000 Symposium on Eye Tracking Research and Applications (pp. 71-78). Palm Beach Gardens, FL, USA: ACM. doi:10.1145/355017.355028

Sarter, N. B., Mumaw, R. J., \& Wickens, C. D. (2007). Pilots' monitoring strategies and performance on automated flight decks: An empirical study combining behavioral and eye-tracking data. Human factors, 49(3), 347-357. doi: 10.1518/001872007X196685.

Vaidya, A., Lee, S., \& Hwang, I. (2016). Data-driven modeling and analysis framework for cockpit human-machine interaction issues. Journal of Aerospace Information Systems, 9(13), 370-380. doi:10.2514/1.I010466

Van de Merwe, K., Van Dijk, H., \& Zon, R. (2012). Eye Movements as an Indicator of Situation Awareness in a Flight Simulator Experiment. The International Journal of Aviation Psychology, 22(1), 78-95. doi:10.1080/10508414.2012.635129

Wang, J. T. (2011). Pupil dilation and eye tracking. In Handbook of Process-Tracing Method (pp. 185-204). London, United Kingdom: Psychology Press.

Wang, T., Li, W. C., \& Lin, J. (2017). Lessons Learned from GE-235: Integrated Pilots' Visual Parameters into Cockpit Recorders for Accident Investigation and 
Prevention. Paper presented at the 2017 International Society of Air Safety Investigators Conference, San Diego, USA.

Yu, C. S., Wang, E. M., Li, W. C. \& Braithwaite, G. (2014). Pilots' Visual Scan Pattern and Situation Awareness in Flight Operations. Aerospace Medicine and Human Performance, 85(7), 708-714. doi:10.3357/ASEM.3847.2014 


\title{
The benefits of integrated eye tracking
}

\section{with airborne image recorders in the \\ flight deck: a rejected landing case study}

\author{
Li, Wen-Chin
}

Elsevier

Li W-C, Braithwaite G, Wang T, et al., (2020) The benefits of integrated eye tracking with airborne image recorders in the flight deck: a rejected landing case study. International Journal of Industrial Ergonomics, Volume 78, July 2020, Article number 102982

https://doi.org/10.1016/j.ergon.2020.102982

Downloaded from Cranfield Library Services E-Repository 